\title{
Perbandingan Pemberian Parecoxib Na 40 mg Intravena Preoperatif dengan Pascaoperatif dalam Penatalaksanaan Nyeri Pascaoperatif pada Operasi Laparotomi Ginekologis
}

\author{
Ardhana Risworo Anom Yuswono, ${ }^{1}$ Tinni T. Maskoen, ${ }^{2}$ Iwan Fuadi ${ }^{2}$ \\ ${ }^{1}$ Bagian Anestesi dan Terapi Intensif Rumah Sakit Paru Goenawan Cisarua Bogor, \\ ${ }^{2}$ Departemen Anestesiologi dan Terapi Intensif \\ Fakultas Kedokteran Universitas Padjadjaran/Rumah Sakit Dr. Hasan Sadikin Bandung
}

\begin{abstract}
Abstrak
Multimodal analgesia dan preemptive analgesia menjadi terapi yang efektif dalam penatalaksanaan nyeri pascaoperatif. Tujuan penelitian ini adalah untuk menganalisis perbandingan pemberian parecoxib $\mathrm{Na}$ $40 \mathrm{mg}$ intravena preoperatif dengan pascaoperatif terhadap nilai NRS. Penelitian ekperimental dengan rancangan analisis komparatif dilaksanakan dari Maret-Juni 2013. Subjek adalah wanita usia 18-60 tahun yang menjalani operasi laparatomi ginekologis dengan anestesi umum di Rumah Sakit Dr. Hasan Sadikin Bandung. Subjek terdiri atas 18 orang pada masing masing kelompok. Parecoxib Na 40 mg diberikan pada dua kelompok perlakuan, yaitu pre atau pascaoperatif. Tramadol $200 \mathrm{mg}$ diberikan pascaoperatif pada semua kelompok dan dilakukan penilaian NRS di ruang pemulihan. Nilai NRS 1 lebih banyak ditemukan pada kelompok I, nilai NRS 3 lebih banyak didapatkan pada kelompok II. Nilai NRS pada kelompok I didapatkan nyeri ringan 15 orang dan nyeri sedang 3 orang. Pada kelompok II didapatkan nyeri ringan 15 orang dan nyeri sedang 3 orang, berdasarkan analisis uji chi-kuadrat tidak terdapat perbedaan nilai NRS kedua kelompok. Tidak didapatkan subjek yang memerlukan analgetik tambahan. Simpulan penelitian ini adalah bahwa tidak terdapat perbedaan antara pemberian parecoxib $\mathrm{Na} 40 \mathrm{mg}$ preoperatif dan pascaoperatif dalam penatalaksanaan nyeri pascaoperatif. Efek analgetik yang lebih baik didapatkan pada pemberian parecoxib Na preoperatif dengan nilai NRS yang lebih rendah.
\end{abstract}

Kata kunci: Laparatomi ginekologis, numerical rating scale, parecoxib $\mathrm{Na}$, preoperatif, pascaoperatif

\section{Comparison of Pre-operative and Post-operative Intravenous $40 \mathrm{mg}$ Parecoxib Na in Gynecologic Laparatomy Surgery Post-Operative Pain Management}

\begin{abstract}
Multimodal analgesia regimens and preemptive analgesia will improve post- operative pain relief. The purpose of this study was to compare pre- and post- operative parecoxib $40 \mathrm{mg}$ intravenous to NRS value. This experimental study with comparative analytical method was conducted in women 18 to 60 years old who underwent gynecologic laparatomy at Dr. Hasan Sadikin General Hospital Bandung during the period of March to June 2013. Subjects consisted of 18 women for each pre-operative and post-operative group. Parecoxib $40 \mathrm{mg}$ were given to the two groups, pre-operative (group I) and post-operative (group II), while intravenous tramadol $200 \mathrm{mg}$ was also also given to all groups post-operatively. The NRS was calculated at recovery room. NRS value 1 was more frequent in group I while the NRS value 3 more frequent in group II. NRS values in group I: 15 with mild pain (83.3\%), 3 with moderate pain (16.7\%). In group II the values were 15 with mild pain (83.3\%), 3 with moderate pain (16.7\%), which was not significant. In conclusion, there is no difference between pre-operative and post-operative parecoxib sodium $40 \mathrm{mg}$ for post operative pain management. There is a better analgetic effect in the group with pre-operative parecoxib which is apparent from lower NRS.
\end{abstract}

Key words: Gynecological laparatomy, numerical rating scale, parecoxib Na, post operative, pre operative

Korespondensi: Ardhana Risworo Anom Yuwono, dr., SpAn. M. Kes, Bagian Anestesi dan Terapi Intensif Rumah Sakit Paru M. Goenawan Partowidigdo, Jl. Raya Puncak km. 83 Cisarua Bogor, Mobile 081320781993, Email anom021@yahoo.com 


\section{Pendahuluan}

Laparatomiginekologismempunyairisikonyeri pascaoperatif derajat sedang sampai berat, ${ }^{1,2}$ sehingga memerlukan penatalaksanaan nyeri pascaoperatif yang baik untuk mendapatkan keluaran yang optimal. Penatalaksanaan nyeri pascaoperatifyang efektif dapat dicapai dengan mengombinasikan analgesia multimodal serta preemptive analgesia. Analgesia multimodal dicapai dengan mengombinasikan opioid dan nonopioid yang bekerja pada tempat berbeda yaitu pada sistem saraf pusat dan juga perifer dengan tujuan meningkatkan kontrol nyeri dan menurunkan efek samping yang berhubungan dengan opioid. ${ }^{3,4}$

Preemptive analgesia adalah metode terapi nyeri pascaoperatif yang cukup efektif, dimulai sebelum insisi operasi serta berfungsi selama periode pembedahan hingga pascaoperatif. ${ }^{5,6}$ Untukmenentukan terapidanjuga pemantauan efektivitas analgetika, dibutuhkan instrumen untuk menilai intensitas nyeri pascaoperatif. Salah satu instrumen yang dapat dipergunakan untuk menilai derajat nyeri adalah numerical rating scale (NRS), dengan skala 0-10 yang menggambarkan intensitas nyeri dengan skala 'tidak ada nyeri' hingga "nyeri terburuk yang dapat dibayangkan",7,8

Parecoxib sebagai golongan inhibitor COX2 , menghilangkan nyeri akut dengan cepat dan efektif untuk penggunaan jangka pendek pada berbagai macam kasus bedah ginekologis. ${ }^{1,9,10}$ Pada operasi laparatomi ginekologis, parecoxib pascaoperatif akan memberikan efek analgesia yang sama dengan morfin dan dypyrone serta mengurangi penggunaan morfin. ${ }^{9,11,12}$ Tujuan penelitian ini untuk mengukur perbedaan efek pemberian parecoxib $\mathrm{Na} 40 \mathrm{mg}$ saat preoperatif dengan pascaoperatif pada operasi laparatomi ginekologis.

\section{Subjek dan Metode}

Jenis penelitian merupakan uji eksperimental dengan analitik komparatif yang dilaksanakan dari Maret sampai dengan Juni 2013. Subjek penelitian merupakan pasien yang menjalani operasi laparatomi ginekologis di Rumah Sakit Dr. Hasan Sadikin Bandung. Penelitian ini telah mendapat persetujuan Komite Etik Penelitian Kesehatan Fakultas Kedokteran Universitas Padjadjaran Bandung/Rumah Sakit Dr. Hasan Sadikin Bandung. Kriteria inklusi ialah wanita 18-60 tahun, status fisik American Society of Anesthesiologist (ASA) I-II, operasi laparatomi ginekologis dalam anestesia umum. Kriteria eksklusi ialah terdapat riwayat alergi parecoxib $\mathrm{Na}$ dan juga menggunakan obat antikoagulan. Kriteria pengeluaran ialah pada pasien dengan transfusi darah atau komponen darah yang mengandung faktor pembekuan, penggunaan obat antifibrinolitik, serta operasi lebih dari 4 jam.

Kelompok I mendapatkan Parecoxib $\mathrm{Na} 40$ mg saat 30 menit sebelum insisi, sedangkan kelompok II diberikan saat penutupan luka operasi. Analgetik tambahan berupa tramadol $200 \mathrm{mg}$ diberikan dengan cara drip intravena pada semua subjek setelah operasi. Penilaian NRS dilakukan 30 menit setelah subjek berada di ruang pemulihan. Uji statistika dilakukan mempergunakan uji chi-kuadrat yang diolah dengan program statistical product and servise solution versi 17.0. Jumlah sampel ditentukan berdasarkan pada rumus besar sampel untuk mengetahui perbedaan 2 (dua) perlakuan, dan didapatkan sebanyak 18 subjek pada masingmasing kelompok. Kemaknaan terhadap hasil ditentukan berdasarkan nilai $\mathrm{p}<0,05$.

\section{Hasil}

Selama periode Maret-Juni 2013 didapatkan 36 subjek dengan rentang usia 18-52 tahun yang memenuhi kriteria inklusi. Karakteristik umum subjek penelitian menurut usia, berat badan, dan lama operasi pada kedua kelompok tidak ada perbedaan bermakna (Tabel 1).

Pada masing-masing kelompok didapatkan nilai NRS kategori nyeri ringan dan juga nyeri sedang dengan jumlah yang sama (Tabel 2), dengan nilai skala nyeri adalah 1-4 (Tabel 3). Berdasarkan uji chi-kuadrat, tidak didapatkan perbedaan bermakna pada hasil NRS kedua kelompok dengan nilai $\mathrm{p}=1,000$. 
Tabel 1 Karakteristik Subjek Masing-masing Kelompok

\begin{tabular}{lccc}
\hline \multicolumn{1}{c}{ Karakteristik } & Kelompok I & Kelompok II & Nilai p \\
\hline Usia (tahun) & & & 0,62 \\
Rata-rata (SB) & $37,94(10,78)$ & $39,50(10,23)$ & \\
Median & 40 & 42 & \\
Rentang & $18-52$ & $20-52$ & 0,29 \\
Berat badan (kg) & & & \\
Rata-rata (SB) & $48,72(8,72)$ & $51(5,12)$ & \\
Median & 50 & 51 & 0,72 \\
Rentang & $35-72$ & $40-58$ & \\
Lama operasi (menit) & & & \\
Rata-rata & $112,2(56,83)$ & $105,00(50,90)$ & \\
Median & 110 & 100 & \\
Rentang & $30-240$ & $30-240$ & \\
\hline
\end{tabular}

Keterangan: SB: simpang baku

\section{Pembahasan}

Penelitian ini memakai parecoxib $\mathrm{Na} 40 \mathrm{mg}$ intravena dan juga tramadol $200 \mathrm{mg}$ intravena untuk penatalaksanaan nyeri pascaoperatif. Hal ini merujuk pada penggunaan multimodal dan preemptive analgesia. Kombinasi berbagai jenis analgetikyang bekerja dengan mekanisme serta tempat yang berbeda pada sistem saraf, menghasilkan analgetik yang bersifat aditif atau sinergis dengan efek samping yang lebih rendah jika dibandingkan dengan pemberian 1 (satu) agen analgetik. ${ }^{13} \mathrm{Hal}$ ini dapat dicapai dengan cara mengombinasikan antara opioid dan nonopioid yang bekerja pada tempat yang berbeda pada sistem saraf pusat serta perifer dengan tujuan meningkatkan kontrol nyeri dan menurunkan efek samping yang berhubungan dengan opioid. ${ }^{3,4}$

Preemptive analgesia mencegah sensitisasi sentral yang disebabkan oleh insisi serta jejas inflamasi, diberikan sebelum insisi operasi dan berfungsi selama periode pembedahan hingga pascaoperatif.,56 Konsep preemptive analgesia

Tabel 2 Skala Nyeri berdasarkan NRS pada Kedua Kelompok

\begin{tabular}{lcc}
\hline $\begin{array}{c}\text { Nyeri } \\
\text { berdasarkan NRS }\end{array}$ & $\begin{array}{c}\text { Kelompok } \\
\text { I }\end{array}$ & $\begin{array}{c}\text { Kelompok } \\
\text { II }\end{array}$ \\
\hline Nyeri ringan & 15 & 15 \\
Nyeri sedang & 3 & 3 \\
\hline
\end{tabular}

adalah modulasi nosiseptif perifer dan sentral pada pasien yang sedang menjalani operasi. Preemptive analgesia mengurangi kebutuhan analgetik pascaoperatif. ${ }^{14}$

Penelitian ini menunjukkan efek analgesia yang lebih baik dengan nilai NRS yang rendah pada kedua kelompok perlakuan, walaupun tidak didapatkan perbedaan yang bermakna secara statistika pada kedua kelompok. Hasil NRS pada kedua kelompok termasuk pada nyeri kategori ringan dan juga sedang, hal ini menunjukkan pemberian parecoxib $\mathrm{Na}$ baik saat pre atau pascaoperatif dapat menurunkan derajat nyeri pada laparatomi ginekologis dari sedang sampai berat menjadi ringan sampai sedang. Nilai NRS 1 lebih banyak didapatkan pada subjek di kelompok I ( 3 subjek) dan nilai NRS 4 lebih banyak ditemukan pada kelompok II (9 subjek).

Hasil ini sesuai dengan hasil penelitian pada hip arthoplasty yang menunjukkan pemberian parecoxib saat preoperatif tidak memberikan efek preemptive analgesia, akan tetapi terdapat

Tabel 3 Nilai NRS pada Kedua Kelompok

\begin{tabular}{ccc}
\hline Nilai NRS & Kelompok I & Kelompok II \\
\hline 1 & 3 & 1 \\
2 & 5 & 5 \\
3 & 7 & 9 \\
4 & 3 & 3 \\
\hline
\end{tabular}

Keterangan: nilai NRS 1-3: nyeri ringan, nilai NRS 4-6: nyeri sedang 
kecenderungan peningkatan analgesia segera setelah operasi pada pemberian saat preinsisi, sesuai dengan perkiraan efek analgetik dari NSAID. Pada hasil penelitian tersebut, nilai nyeri kelompok perlakuan lebih rendah bila dibandingkan dengan nilai kelompok kontrol, terdapat kecenderungan efek analgetik yang lebih baik pada pemberian saat preoperatif, tetapi secara statistika tidak didapatkan hasil yang signifikan antara kelompok pre dan pascaoperatif. ${ }^{15}$

Penelitian lain pada dua kelompok subjek dengan histerektomi vaginal yang mendapat parecoxib intraoperatif dan diulang tiap 12 jam pascaoperatif, serta pemberian dypirone intraoperatif yang diulang tiap 6 (enam) jam, menunjukkan nilai visual analogue scale (VAS) yang lebih rendah pada 12 jam pascaoperatif dibandingkan dengan pemberian dypirone. ${ }^{11}$ Penelitian mengenai efek preventif parecoxib pada nyeri pascadisektomi dilakukan tahun 2007. Subjek penelitian ini mendapat parecoxib preoperatif, perioperatif, serta pascaoperatif. Penilaian derajat nyeri, efek samping opioid dan kebutuhan morfin dinilai 24 jam setelah penutupan kulit. Hasil pemberian parecoxib perioperatif dibandingkan dengan kelompok plasebo dan saat pascaoperatif menunjukkan derajat nyeri yang lebih rendah, efek samping opioid dan penggunaan morfin yang juga lebih rendah. Perbandingan antara preoperatif dan perioperatif tidak signifikan. ${ }^{16}$

Pada penelitian ini, tidak terdapat subjek yang memerlukan analgetik tambahan serta tidak terdapat kejadian muntah. Efek analgesia parecoxib juga telah diteliti dalam beberapa penelitian dengan menggunakan subjek yang menjalani laparatomi ginekologis. Penelitian terhadap pasien total abdominal hysterectomy (TAH) dengan anestesi umum menunjukkan pemberian parecoxib $\mathrm{Na} 40 \mathrm{mg}$ intravena preoperatif, yaitu saat induksi anestesi dapat menurunkan intensitas nyeri dan penggunaan morfin yang bermakna dibandingkan dengan pemberian plasebo. ${ }^{12}$

Penelitian yang dilakukan pada laparatomi ginekologis menunjukkan bahwa pemberian parecoxib $\mathrm{Na} 40 \mathrm{mg}$ pascaoperatif ditoleransi dengan baik. Parecoxib mempunyai efektivitas sama dengan ketorolak $30 \mathrm{mg}$ dan superior terhadap morfin $4 \mathrm{mg} .{ }^{1}$ Penelitian yang menilai intensitas nyeri menggunakan VAS pada subjek yang menjalani operasi laparatomi ginekologis menunjukkan pemberian parecoxib $\mathrm{Na} 40 \mathrm{mg}$ pada saat pascaoperatif memiliki efektivitas yang sama dengan pemberian morfin $12 \mathrm{mg}$ serta lebih unggul bila dibandingkan dengan pemberian morfin 6 mg. ${ }^{9}$ Hasil penelitian pada subjek yang menjalani operasi ginekologis mayor dengan anestesia umum, menunjukkan pemberian parecoxib $\mathrm{Na} 40 \mathrm{mg}$ pascaoperatif menurunkan kebutuhan morfin, efek samping opioid, dan juga penggunaan obat tambahan seperti antiemetik serta antipruritus. ${ }^{17}$

\section{Simpulan}

Pemberian parecoxib Na 40 mg antara pre dan pascaoperatif dalam penatalaksanaan nyeri pascaoperatif tidak menunjukkan perbedaan bermakna. Namun, secara klinis pemberian parecoxib pada saat preoperatif menghasilkan analgesia lebih baik yang ditunjukkan dengan nilai NRS yang lebih rendah.

\section{Daftar Pustaka}

1. Barton SF, Langeland FF, Snabes MC, Comte DL, Kuss ME, Dhadda SS, dkk. Efficacy and safety of intravenous parecoxib $\mathrm{Na}$ in relieving acute postoperative pain following gynecologic laparotomy surgery. Anesthesiology. 2002;97:306-14.

2. Bikhazi GB, Snabes MC, Bajwa ZH, Davis DJ, LeComte D, Traylor L, dkk. A clinical trial demonstrates the analgesic activity of intravenous parecoxib sodium compared with ketorolac or morphine after gynecologic surgery with laparotomy. Am J Obst Gynecol. 2004;191:1184-91.

3. White PF, Kehlet H, Neal JM, Schricker T, Carr DB. The role of the anesthesiologist in fast-track surgery: from multimodal analgesia to perioperative medical care. Anesth Analg. 2007;104:1380-96.

4. Brennan F, Carr DB, Cousins M. Pain management: a fundamental human right. 
Anesth Analg. 2007;105:205-21.

5. Kissin I. Preemptive analgesia. Anesthesiology. 2000;93:1138-43.

6. Ong CKS, Lirk P, Seymour RA, Jenkins BJ. The efficacy of preemptive analgesia for acute postoperative pain management: a meta-analysis. Anesth Analg. 2005;100: 757-73.

7. Hjermstad MJ, Fayers PM, Haugen DF, Caraceni A, Hanks G, Loge JH, dkk. Studies comparing numerical rating scales, verbal rating scales, and visual analogue. scales for assessment of pain intensity in adults: a systematic literature review. J Pain Symptom Manage. 2011;41:1073-93.

8. Hawker GA, Mian S, Kendzerska T, French M. Measures of adult pain. Arthritis Care Research. 2011;63:S240-52.

9. Malan TP, Gordon S, Hubbard R, Snabes M. The cyclooxygenase-2-specific inhibitor parecoxib sodium is as effective as $12 \mathrm{mg}$ of morphine administered intramuscularly for treating pain after gynecologic laparotomy surgery. Anesth Analg. 2005;100:454-60.

10. Hubbard RC, Naumann TM, Traylor L, Dhadda S. Parecoxib sodium has opioidsparing effects in patients undergoing total knee arthroplasty under spinal anaesthesia. Br J Anaesth. 2003;2:166-72.

11. Soltesz S, Gerbershagen MU, Pantke B,
Eichler F, Molter G. Parecoxib versus dipyrone (metamizole) for postoperative pain relief after hysterectomy. Clin Drug Invest. 2008;28:421-42.

12. Ng A, Smith G, Davidson AC. Analgesic effects of parecoxib following total abdominal hysterectomy. Br J Anaesth. 2003;90(6):746-9.

13. Buvanendran A, Kroin JS. Multimodal analgesia for controlling acute post operative pain. Curr Opin Anaesthesiol. 2009;22:588-93.

14. Morgan GE, Mikhail MS, Murray MJ. Clinical anesthesiology. Edisi ke-4. New York: Appleton and Lange; 2006.

15. Martinez V, Belbachir A, Jaber A, Cherif $\mathrm{K}$, Jamal A, Ozier Y, dkk. The influence of timing of administration on the analgesic efficacy of parecoxib in orthopedic surgery. Anesth Analg. 2007;104:1521-7.

16. Riest G, Peters J, Weiss M, Dreyer S, Klassen PD, Stegen B, dkk. Preventive effects of perioperative parecoxib on post-discectomy pain. Br J Anaesth. 2008; 100:256-62.

17. Tang J, Li S, White PF, Chen X, Wender $\mathrm{RH}$, Quon R, dkk. Effect of parecoxib, a novel intravenous cyclooxygenase $\backslash$ type2 inhibitor, on the postoperative opioid requirement and quality of pain control. Anesthesiology. 2002;96:1305-9. 